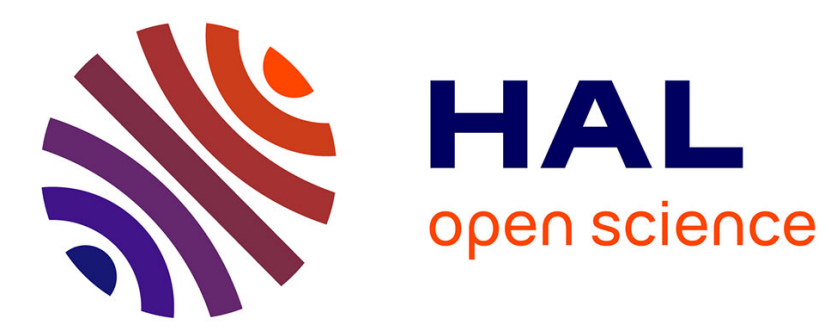

\title{
STUDY OF DISLOCATION - POINT DEFECTS INTERACTION IN MgO SINGLE CRYSTALS BY INTERNAL FRICTION
}

\author{
M. Gabbay, Gilbert Fantozzi
}

\section{> To cite this version:}

M. Gabbay, Gilbert Fantozzi. STUDY OF DISLOCATION - POINT DEFECTS INTERACTION IN MgO SINGLE CRYSTALS BY INTERNAL FRICTION. Journal de Physique Colloques, 1981, 42 (C3), pp.C3-31-C3-41. 10.1051/jphyscol:1981303 . jpa-00220694

HAL Id: jpa-00220694 https://hal.science/jpa-00220694

Submitted on 1 Jan 1981

HAL is a multi-disciplinary open access archive for the deposit and dissemination of scientific research documents, whether they are published or not. The documents may come from teaching and research institutions in France or abroad, or from public or private research centers.
L'archive ouverte pluridisciplinaire HAL, est destinée au dépôt et à la diffusion de documents scientifiques de niveau recherche, publiés ou non, émanant des établissements d'enseignement et de recherche français ou étrangers, des laboratoires publics ou privés. 
JOURNAL DE PHYSIQUE

Colloque C3, supplément au $n^{\circ} 6$, Tome 42, juin 1981

page $\mathrm{C} 3-31$

\title{
STUDY OF DISLOCATION - POINT DEFECTS INTERACTION IN MgO SINGLE CRYSTALS BY INTERNAL FRICTION
}

\author{
M. Gabbay and G. Fantozzi \\ Groupe d'Etudes de Métalzurgie Physique et de Physique des matémiaux, \\ I.N.S.A. Lyon, Bâtiment 502, 20, Avenue A. Einstein, 69621 Vizieurbanne \\ Cedex, France
}

\begin{abstract}
Résumé.- Après déformation plastique, on observe une restauration du Frottement Intérieur (F.I.) lors des recuits, due au piégeage des dislocations par des défauts ponctuels. Cette arrivée des défauts ponctuels sur les dislocations provoque I'apparition d'un phénomène de désancrage thermomécanique sous 1 'effet de la contrainte de sollicitation. Nous avons étudié ce phénomène de désancrage responsable du F.I. $\Delta_{\mathrm{H}}$ dépendant de $1^{\prime}$ amplitude. Pour cela, nous avons déterminé la variation de $\Delta_{H}$ avec $l^{\prime}$ amplitude de vibration $\varepsilon$ soit en fonction de la température de mesure, soit en fonction de la température de recuit. Nous avons tenté d'interprêter nos résultats expérimentaux en fonction des divers modèles de désancrage (modèles de Granato-Lücke et de Teutonico, Granato et Lücke). Notre analyse montre qu'il est nécessaire de tenir compte de l'activation thermique pour rendre compte correctement de nos résultats et nous obtenons ainsi une valeur de l'énergie d'interaction dislocation-défauts ponctuels de l'ordre de $0,4 \mathrm{eV}$.
\end{abstract}

\begin{abstract}
After plastic deformation, an Interna1 Friction (I.F.) recovery is observed during annealing, due to the pinning of dislocations by point defects. This pinning induces thermomechanical breakaway under stress of vibration. We have studied this breakaway phenomenon responsible of amplitude dependent I.F. $\Delta_{H}$. We have determined the variation of $\Delta_{H}$ versus strain amplitude $\varepsilon$ either as a function of measurement temperature or as a function of annealing temperature. We have tried to interpret our experimental results according to various breakaway models (model of Granato-Lücke and model of Teutonico, Granato, Lücke). Our analysis shows that thermal activation has to be taken into account and so we have obtained a value for interaction energy between dislocation - point defects of about $0.4 \mathrm{eV}$.
\end{abstract}

1. Introduction.- In previous papers $/ 1,2 /$, we have already presented some aspects of the behaviour of mobile dislocations in Mgo single crystals studied by Internal friction (I.F.). Among the main results of this study, it is useful to point out the high sensitivity of I.F. (due to dislocations) to annealing which begins to be operative just above Room Temperature (R.T.) - dislocatjons are introduced by plastic deformation at R.T.-.

After heating at $670 \mathrm{~K}$, dislocation damping is considerably reduced; we know that, in this annealing temperature range, the dislocation network is not modified. So, we have naturally suggested that this $I . F$. recovery consecutive to annealing is due to dislocation pinning by point defects. Migration energy $\mathrm{E}_{\mathrm{m}}$ of these point defects has 
been determined by analysis of annealing kinetics; along the most part of the annealing temperature range, the value for $\mathrm{E}_{\mathrm{m}}$ remains between $1.5 \mathrm{eV}$ and $1.8 \mathrm{eV}$. As $1.56 \mathrm{eV}$ is the migration energy for cation vacancy /3/ so, we have confirmed that cation vacancy is the mobile entity which makes easier the migration of many others point defects such as vacancy pairs or impurity vacancy complexes. It is of interest now, to determine the binding energy between dislocations and pinning point defects. So, we have firstly recorded amplitude dependent I.F. versus strain amplitude. Then we have attempted to apply to these experimental results, some classical models of thermomechanical breakaway .

2. Experimental details and results.- Mgo single crystals are cleaved along (100) faces (dimensions : $40 \times 4 \times 2 \mathrm{~mm}^{3}$ ). They are plastically deformed in compression along the longest axis of $2 \%$. They are excited electrostatically in their fundamental flexural mode of vibration at $10 \mathrm{kHz}$. Further details concerning preparation, thermal treatment, plastic deformation of specimens and I.F. measurements are presented elsewhere /4/. Amplitude dependent I.F. $\Delta_{\mathrm{H}}$ is obtained from the total decrement $\Delta$ by subtracting the amplitude independent decrement $\Delta_{I}$. Strain amplitude $\varepsilon$ due to flexural vibration is non uniform along the length and the thickness of specimens; $\varepsilon_{O}$ is calculated as the maximum value of strain amplitude in the specimen.

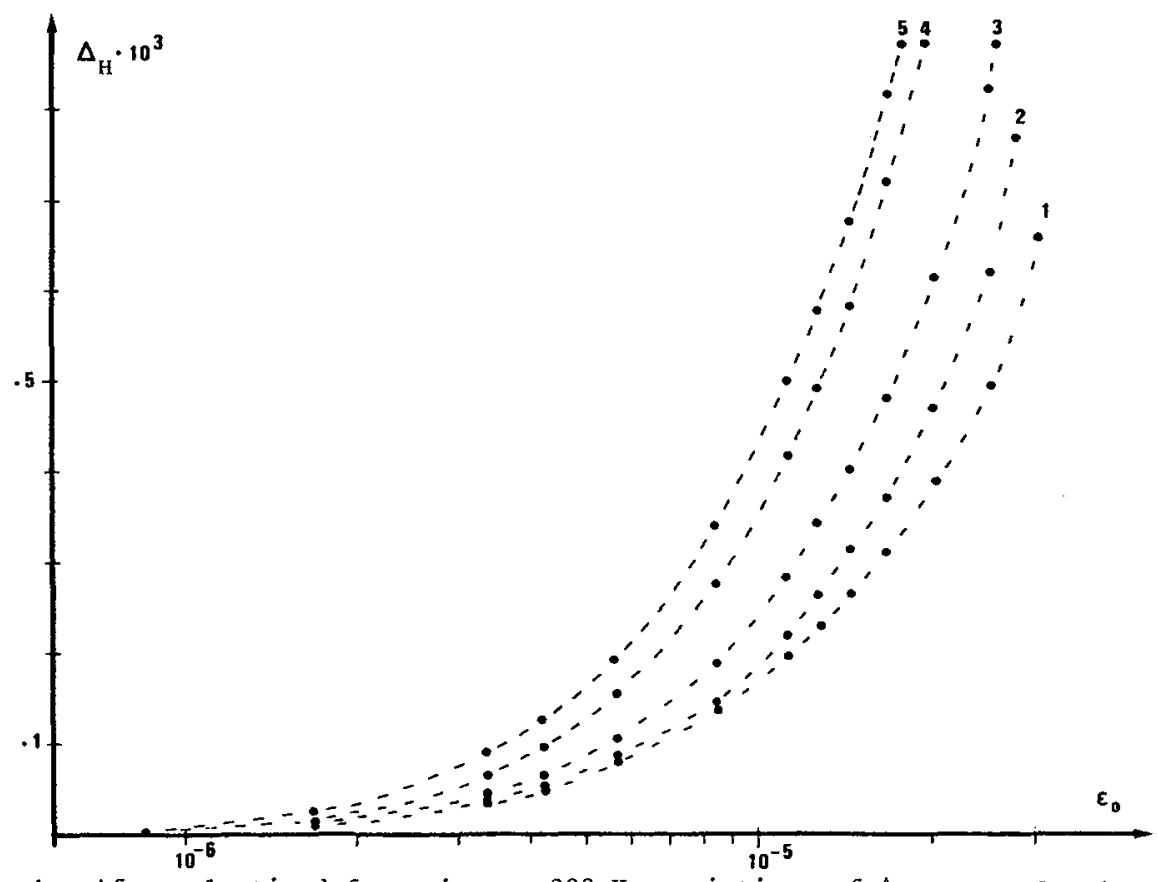

Fig. 1.- After plastic deformation at $293 \mathrm{~K}$, variations of $\Delta_{\mathrm{H}}$ versus $\varepsilon_{\mathrm{O}}$ at various temperatures: $1: 77 \mathrm{~K}, 2: 121 \mathrm{~K}, 3: 145 \mathrm{~K}, 4: 195 \mathrm{~K}, 5: 227 \mathrm{~K}$. 
Figure 1 shows a typical set of curves of amplitude dependent I.F. $\Delta \mathrm{H}$ plotted against strain amplitude $\varepsilon_{0}$ for various measurement temperatures ranging from $77 \mathrm{~K}$ to $293 \mathrm{~K}$. These curves are obtained immediately after plastic deformation. We can notice that for a given strain, the magnitude of $\Delta_{H}$ increases with increasing temperature, suggesting that more dislocations are depinned at higher temperatures. Three similar sets of curves are obtained for different annealing states of the specimen. $\left(\mathrm{T}_{\mathrm{a}}=422 \mathrm{~K}, 540 \mathrm{~K}, 589 \mathrm{~K}\right)$. The general level of $\Delta_{\mathrm{H}}$ decreases while annealing temperature increases. Figures $2,3,4$ show the results corresponding to the above mentioned annealing states.

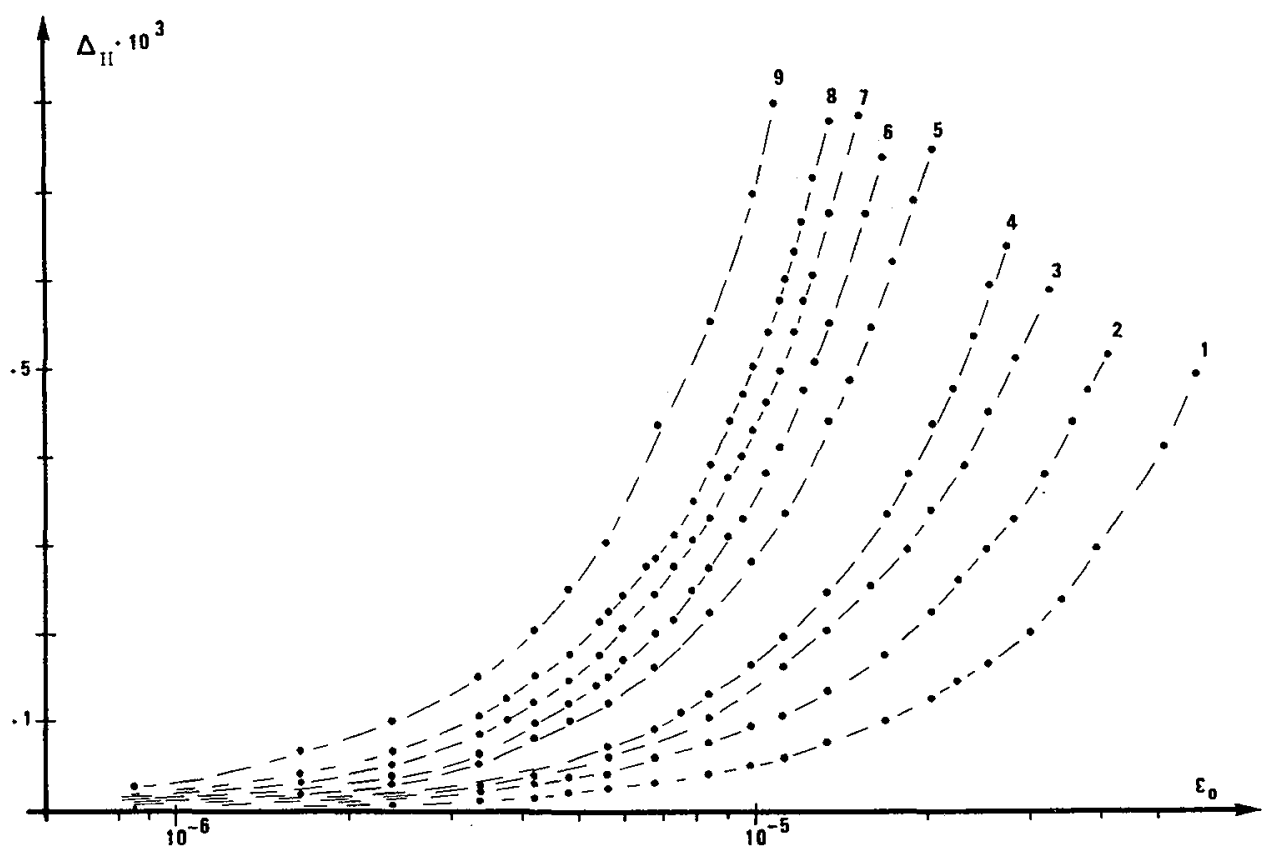

Fig. 2.- After annealing at $422 \mathrm{~K}$, variations of $\Delta_{\mathrm{H}}$ versus $\varepsilon_{\mathrm{O}}$ at various temperatures. $1: 77 \mathrm{~K}, 2: 117 \mathrm{~K}, 3: 149 \mathrm{~K}, 4: 182 \mathrm{~K}, 5: 296 \mathrm{~K}, 6: 348 \mathrm{~K}, 7: 378 \mathrm{~K}$ $8: 388 \mathrm{k}, 9: 421 \mathrm{k}$. 


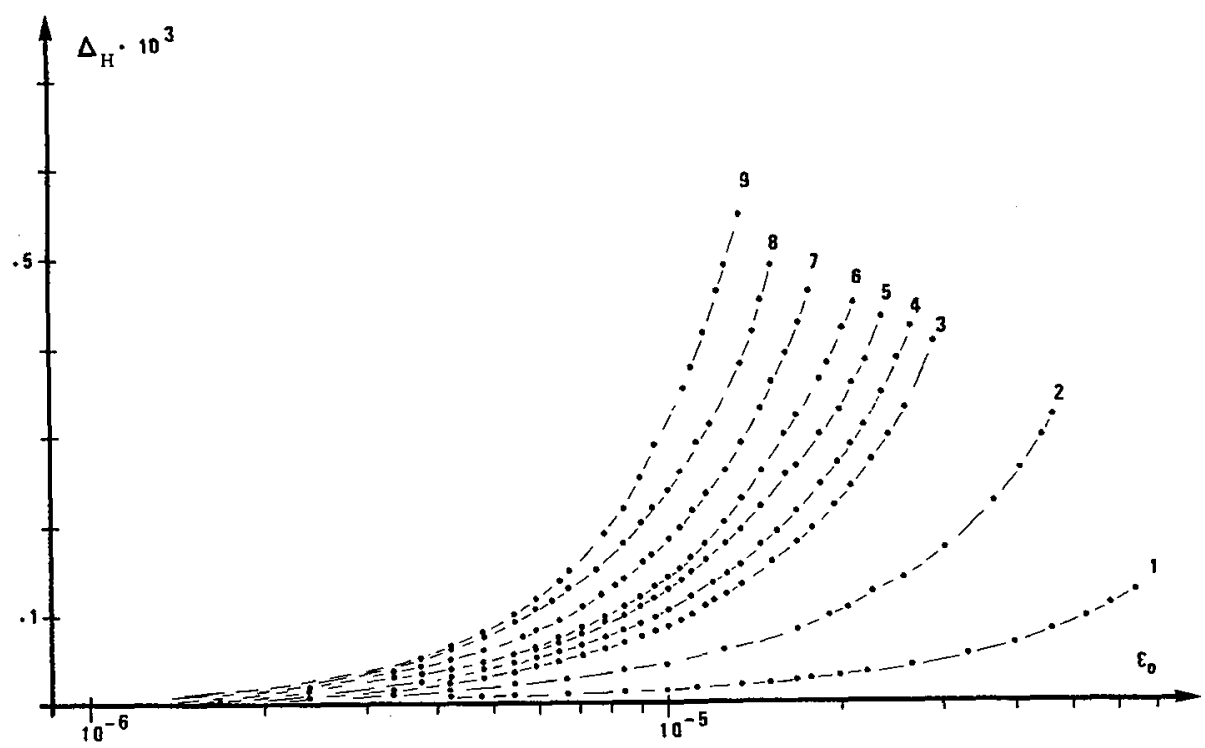

Fig. 3.- After annealing at $540 \mathrm{~K}$, variations of $\Delta_{\mathrm{H}}$ versus $\varepsilon_{\mathrm{O}}$ at various temperatures. $1: 77 \mathrm{~K}, 2: 148 \mathrm{~K}, 3: 291 \mathrm{~K}, 4: 361 \mathrm{~K}, 5: 380 \mathrm{~K}, 6: 412 \mathrm{~K}, 7: 473 \mathrm{~K}$ $8: 503 \mathrm{~K}, 9: 540 \mathrm{~K}$.

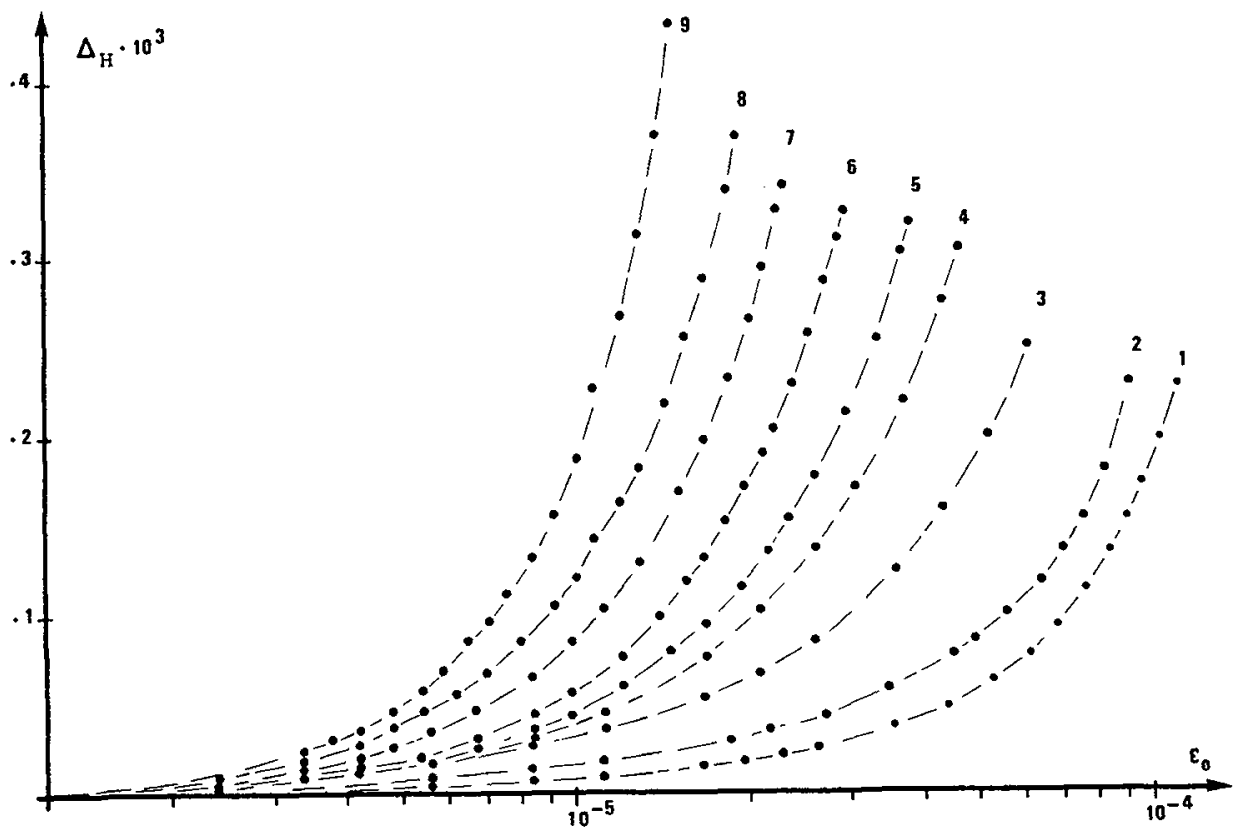

Fig. 4.- After annealing at $589 \mathrm{~K}$, variations of $\Delta_{\mathrm{H}}$ versus $\varepsilon_{\mathrm{O}}$ at various temperatures. $1: 77 \mathrm{~K}, 2: 111 \mathrm{~K}, 3: 136 \mathrm{k}, 4: 207 \mathrm{~K}, 5: 291 \mathrm{~K}, 6: 411 \mathrm{~K}, 7: 498 \mathrm{~K}$, $8: 269 \mathrm{~K}, 9: 589 \mathrm{~K}$. 
3. Analysis of the results and discussion.- Many theoretical models have been developed in order to interpret dislocation breakaway thermally activated or not; most of them have been reviewed by Perez et al. $/ 5 /$. We have used some of these models from which it is expected to deduce the interaction energy between dislocations and pinning point defects.

Firstly, the classicail Granato-Lücke / $6 /$ model has been used for one set of $\Delta_{\mathrm{H}}\left(\varepsilon_{\mathrm{O}}\right)$ curves obtained after annealing at $589 \mathrm{~K}$.

Amplitude dependent I.F. $\Delta_{\mathrm{H}}$ is given by the expression:

$$
\Delta_{H}=\frac{\Lambda L_{N}^{3} A_{1}}{L_{C}^{3 / 2} \varepsilon_{0}^{1 / 2}} \exp \left[-\frac{A_{2}}{L_{C} \varepsilon_{0}}\right]
$$

where $\Lambda$ is the density of dislocation free to vibrate.

$I_{N}$ is the dislocation length between unbreakable nodes.

$I_{C}$ is the disiocation length between adjacent pinning points. $A_{1}$ and $A_{2}$ are constants involving geometric and orientation parameters and the pinning force between point defect and dislocation.

Expression (1) shows that through the exponential dependence of $\Delta_{H}$ on $L_{C}$ any factor which causes $L_{C}$ to decrease also causes $\Delta_{H}$ to decrease. $I_{C}$ is given by:

$$
I_{C}=\frac{b}{c_{O}} \exp \left[-\frac{w_{M}}{k T}\right]
$$

where $W_{M}$ is the dislocation-point defect interaction energy

$\mathrm{C}_{\mathrm{O}}$ is the average concentration of point defects in the lattice.

The relations (1) and (2) provide the connecting link between dislocation damping and interaction energy. If this analysis is valid, a plot of $\ln \left(\Delta_{\mathrm{H}} \varepsilon_{\mathrm{O}}{ }^{1 / 2}\right)$ versus $\frac{1}{\varepsilon_{0}}$ will be in the form of a straight line, the slope of which is $\frac{A_{2}}{L_{C}}$. So, the plot of $\ln \frac{A_{2}}{L_{C}}$ versus $\frac{1}{T}$ should be also in the form of a straight line from which slope, a value of the interaction energy $W_{M}$ will be deduced.

As we can see of figure 5, the G.L. model do not fit very well our results. The G.I. plots fall into straight lines only at the beginning of the $\frac{1}{\varepsilon_{0}}$ range. Nevertheless, the slopes of these lines have been calculated and the figure 6 shows the plot of $\left(\ln \frac{A_{2}}{L_{C}}\right.$ ) versus $\frac{1}{T}$ from which we have obtained $0.035 \mathrm{eV}$ for the interaction energy $W_{M}$. The Granato-Lücke model which does not take into account thermal activation is not very well verified by our results and leads to a very low value of interaction energy. 


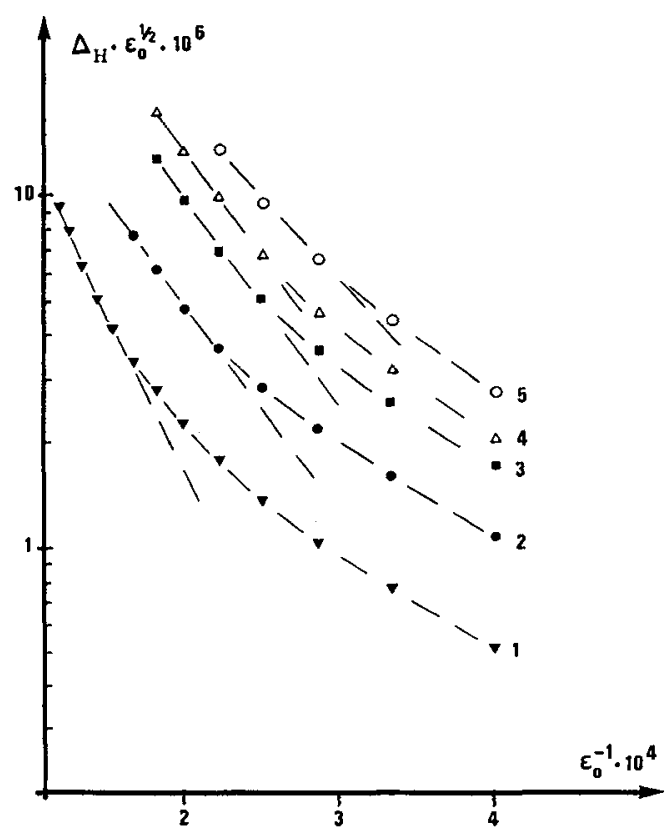

Fig. 5.- After annealing at $589 \mathrm{~K}$, Granato-Lücke plots, according to relation (1) at various temperatures. $1: 291 \mathrm{~K}, 2: 411 \mathrm{~K}, 3: 500 \mathrm{~K}, 4: 519 \mathrm{~K}, 5: 589 \mathrm{~K}$.

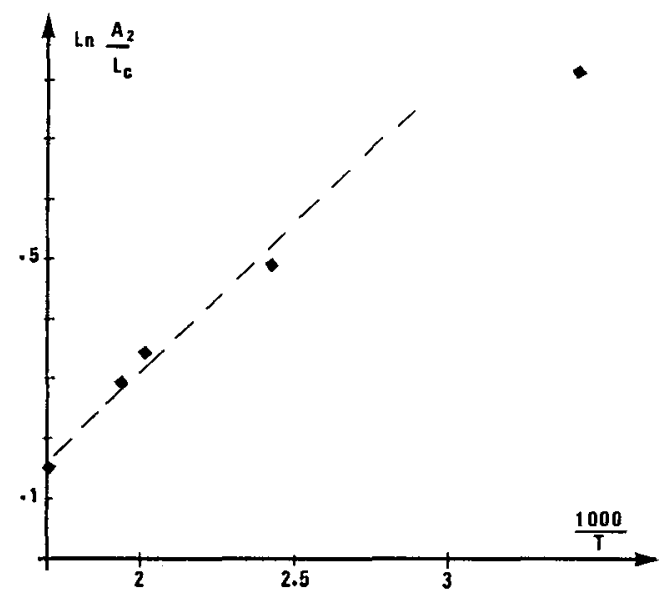

Fig. 6.- Logarithmic plots according to relation (2) in order to obtain interaction energy. 
Then, we have used models in which thermal activation is taken into account. The most part of them are based on the results of Teutonico et a1. /7/. concerning thermomechanical breakaway of a dislocation pinned by a single pinning point. Activation energies for depinning and repinning are determined from the value of the potential energy of the dislocation-pinning point system.

Saul and Bauer /8/ have obtained for amplitude dependent I.F. $\Delta \mathrm{H}$ the following expression:

$$
\Delta_{\mathrm{H}}=\Delta_{0} \exp \left[-\frac{\mathrm{W}_{\mathrm{M}}-\sigma \mathrm{V}}{\mathrm{kT}}\right]
$$

where $\sigma$ is the resolved shear stress acting on a dislocation.

$\mathrm{v}$ is the activation volume.

$\Delta_{\mathrm{O}}$ is the relaxation strength factor (proportional to $\Lambda \mathrm{I}_{\mathrm{N}}^{3} / \mathrm{L}_{\mathrm{C}}^{2}$ ).

For early states of depinning i.e. for the case where the fraction of unpinned network length $f(t)$ is small $(f(t) \ll 1$ ) and for high temperature $(\sigma \mathrm{V}<<\mathrm{kT})$ the relation (3) becomes:

$$
\Delta_{\mathrm{H}}=\Delta_{\mathrm{O}}\left[1+\frac{\sigma \mathrm{V}}{\mathrm{kT}}\right] \exp \left[-\frac{W_{\mathrm{M}}}{\mathrm{kT}}\right]
$$

Therefore, $\Delta_{\mathrm{H}}(T)$ is expected to vary nearly exponentially with $\frac{1}{T}$, for low values of $\Delta_{\mathrm{H}}$.

Such an expected result can be also deduced from the model proposed by Friedel $/ 9 /$. In this model, the activation energy for breakaway is given by:

$$
E(\sigma)=W_{M}-\sigma b d I_{C}
$$

where $d$ is the width of point defect.

The amplitude dependent I.F. $\Delta_{H}$ is;

$$
\Delta_{H}=\Delta_{O} \exp \left[-\frac{W_{M}-\sigma_{O} b d L_{C}}{k T}\right]
$$

This relation is not valid in the low stresses range because dislocation repinning is not taken into account. It is supposed also that the depinning of the first pinning point occurs at a frequency much lower than the depinning frequency of the following points.

Figure 7 shows that the plot of $\ln \Delta_{H}$ versus $\frac{1}{T}$ does not fall into straight lines along the temperature range. Here again, these two similar models are not verified completely. Nevertheless, the interaction energy deduced from this plot is $0.1 \mathrm{eV}$; this value seems to be too low comparatively to the temperature range in which I.F. is 
amplitude dependent.

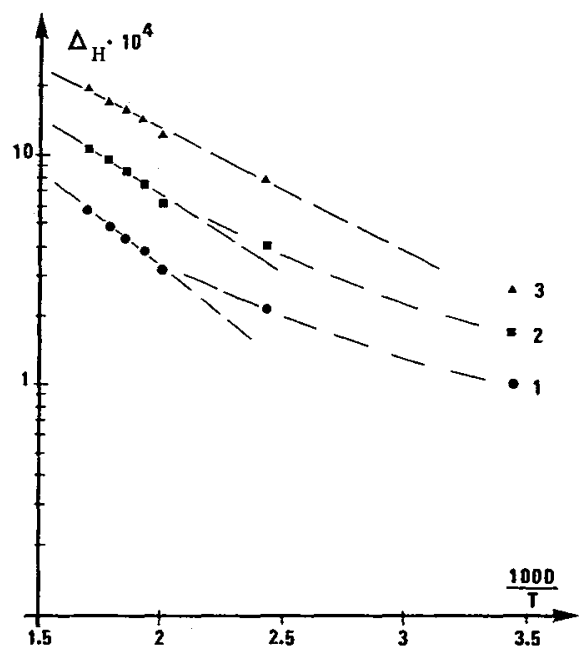

Fig. 7.- According to relation (4), logarithmic plots of $\Delta_{H}$ versus $\frac{1000}{T}$ at various strain amplitudes. $1: \varepsilon_{\mathrm{o}}=2.5 \times 10^{-5}, 2: \varepsilon_{\mathrm{o}}=3.5 \times 10^{-5}, 3: \varepsilon_{\mathrm{o}}=4.5 \times 10^{-5}$.

For this reason, we have tried the model proposed by Lücke et al. $/ 10 /$. These authors have used the results of Teutonico et al. /6/ for the determination of amplitude dependent I.F. $\Delta_{H}$. The following relation gives the variation of $\Delta_{H}$ as a function of the parameter $\tau$ determined by the applied stress, temperature and frequency.

$$
\Delta_{\mathrm{H}}(\tau)=\Lambda \mathrm{L}^{2}\left(\frac{1+\tau}{\tau}\right) \exp \left[-\frac{1}{\tau}\right]
$$

where

$$
\tau=\frac{L}{I_{0}}=\frac{\sigma_{0}}{\sigma_{T_{1}, L}}
$$

$L$ is the average length of dislocation loop.

$1_{0}$ is the minimum loop length under which breakaway cannot occur for $\sigma=\sigma_{0}$ at a given temperature.

$$
\begin{gathered}
\sigma_{\mathrm{T}_{1}, L} \text { is given by: } \\
\sigma_{T_{1}, L}=\sigma_{1}\left\{1-\left[\left(\frac{\mathrm{kT}}{\mathrm{U}_{0}}\right) \text { In }\left\{\left(\frac{\nu_{1} \sigma_{1}}{8 \nu}\right) \frac{\mathrm{kT}}{\sigma_{0}}\right\}\right]^{1 / 2}\right\}
\end{gathered}
$$

$v_{1}$ is the attempt frequency.

$v$ is the vibration Erequency. 


$$
\begin{aligned}
& \sigma_{1} \sim \frac{U_{0}}{b^{2} L} \quad \text { is the mechanical depinning stress. } \\
& U_{0} \quad \text { is the activation energy for breakaway. }
\end{aligned}
$$

For a given value of $\Delta_{H^{\prime}}$, the corresponding strain amplitude $\varepsilon_{0}$ can be expressed as a function of temperature according to the following relation /11/:

$$
\varepsilon_{O}=\frac{\sigma_{O}}{\mathrm{Y}}=\frac{\lambda}{\mathrm{Y}} \frac{\mathrm{U}_{\mathrm{O}}}{\mathrm{b}^{2} \mathrm{~L}}\left[1-\frac{(\mathrm{T}}{\mathrm{T}_{\mathrm{C}}}\right]^{1 / 2}
$$

with

$$
\left.\mathrm{T}_{\mathrm{C}}=\frac{\mathrm{U}_{\mathrm{O}}}{\mathrm{k}} \frac{1}{\ln \left\{\left(\frac{\nu_{1} \sigma_{1}}{8 \nu \sigma_{0}}\right) \frac{\mathrm{kT}}{\mathrm{U}_{0}}\right.}\right\}
$$

$\mathrm{Y}$ is the Young's modulus.

$\lambda$ is a constant which depends on $\Delta_{\mathrm{H}}\left(\lambda=0.36\right.$ when $\Delta_{\mathrm{H}}$ is maximum). In our case $\lambda$ has been estimated at 0.2 for $\Delta_{\mathrm{H}}=$ $0.7 \times 10^{-3}$.

So the plot of $\varepsilon_{0}$ versus $T^{1 / 2}$ should give a straight line from which the temperature $T_{C}$ is deduced and consequently the activation energy $U_{O} \simeq 20 \mathrm{kT}$. Furthermore, the slope gives the activation volume $b^{2} \mathrm{~L}$.

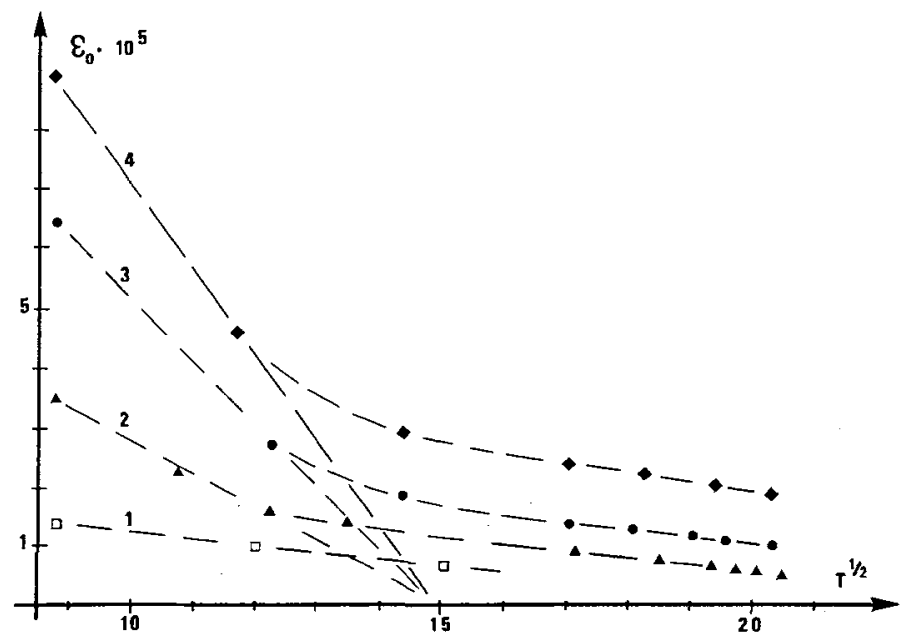

Fig. 8.- According to relation (9), plot of $\varepsilon_{\mathrm{o}}$ versus $\mathrm{T}^{1 / 2}$, at constant $\Delta_{\mathrm{H}}=$ $0.7 \times 10^{-3}$ and for various annealing temperature. $1: 293 \mathrm{~K}, 2: 422 \mathrm{~K}, 3: 540 \mathrm{~K}$ $4: 589 \mathrm{k}$. 
Figure 8 shows plots of $\varepsilon_{0}\left(T^{1 / 2}\right)$ for different annealing states. Each of these plots presents partial linearity in the low temperature range $(T<200 \mathrm{~K})$. The higher the annealing temperature is the stronger the temperature dependence of $\varepsilon_{0}$ is. However the temperature $T_{C}$ remains constant (see figure $8, \mathrm{~T}_{\mathrm{C}}$ can be defined as an intercept with temperature axis of the extrapolation of the linear parts of the $\varepsilon_{0}\left(T^{1 / 2}\right)$ plots).

This remark suggests that, in the low temperature range, dislocations interact with pinning point defects with the same activation energy $U_{O}$ we have obtained $\mathrm{T}_{\mathrm{C}}=225 \mathrm{~K}$ and $\mathrm{U}_{\mathrm{O}}=0.4 \mathrm{eV}$. Thi.s value could correspond to the interaction of cation vacancies or impurity-vacancy complexes as suggested by the value previously obtained for migration energy /3/ and by the calculation of puls /14/.

Then, the activation volume $v$ can be deduced from the slope of the linear parts for each annealing states. We have obtained:

\begin{tabular}{|c|c|c|c|c|}
\hline $\mathrm{T}_{\mathrm{K}}$ & 293 & 422 & 540 & 589 \\
\hline $\mathrm{v}_{\mathrm{cm}}^{3}$ & $34 \times 10^{-22}$ & $6 \times 10^{-22}$ & $3 \times 10^{-22}$ & $2 \times 10^{-22}$ \\
\hline
\end{tabular}

Along the high temperature range ( $\mathrm{T}>200 \mathrm{~K}$ ) the strain amplitude $\varepsilon_{0}$ (needed to obtain a given value of $\Delta_{H}$ ) decreases more and more slowIy while temperature increases. Such a behaviour suggests that another interaction mechanism with higher activation energy is operative.

'The results obtained for activation volume allow to get an idea of the reduction ratio of average length $L$ of free dislocation from a given annealing state to the next one.

We have observed a reduction much more important than the one deduced from the measurements of amplitude independent I.F. $\Delta_{I}$ since $\Delta_{I}$ is proportional to $L^{4} / 6 /$. Such a difference between these two methods could be interpreted either by an asymetrical pinning of dislocation or by the fact that only a small fraction of dislocations is responsible for $\Delta_{\mathrm{H}}$.

We have used various theoretical models and each of them leads to a different value for activation energy. Such a dispersion of the results had been already pointed out by De Batist /12/. The values obtained from the G.L. model and the Saul Bauer model seems to be unrealistic. The analysis deduced from the T.G.L. model gives a more plau sible value of interaction energy, comparatively to the temperature range in which depinning is operative. In order to get a more accurate analysis, a theoretical study of thermomechanical breakaway needs to be 
undertaken. In this study, we intend to use a model previously developed by Vincent et al./13/. I.F. due to dislocation breakaway will be calculated by numerical methods without approximations and the results will be compared to the present experimental results.

\section{References}

/1/ Gabbay, M., Esnouf, C., Fantozzi, G., J. Physique Lett. 39 (1978) L-271

12/ Fantozi, G., Gabbay, M., Internal Friction and Ultrasonic Attenuation in Solids, Editor C.C. Smith, (Pergamon Press, Oxford) 1980, p. 395

/3/ Harding, B.C., Price, D.M. Philos. Mag. 26 (1972) 253

/4/ Gabbay, M., Bonjour, C., Fantozzi, G., Internal Friction and Ultrasonic Attenuation in Solids (University of Tokyo Press) 1977, p. 695

/5/ Perez, J., Peguin, P., Fantozzi, G., Gobin, P.F., Ann. Phys. 5 (1970) 303-352

/6/ Granato, A.V., Liticke, K., J. Appl. Phys. 27 (1956) 583

/7/ Teutonico, L.J., Granato, A., Lücke, K., J. Appl. Phys. 35 (1964) 220

/8/ Saul, R.H., Bauer, C.I., J. Appl. Phys. 39 3 (1968) 1469

19/ Friedel, J., Conference Teddington, Middlesex, 410, 1963

/10/ Lücke, K., Granato, A.V., Teutonico, L.J., J. Appl. Phys. 11 (1.968) 5181

/11/ Fantozzi, G., Thesis,Lyon (1971)

/I2/ De Batist, R., Internal Friction of Structural Defects in Cristalline Solids, (North-Holland Publishing Company) 1972 , p. 374

/13/ Vincent, A., Perez, J., Philos. Mag. A. $\underline{40} 3$ (1979) 377

/14/ Puls, M.P., Philos. Mag. A. 41 (1980) 353-368 